This is a pre-print of an article published in Psychotherapy and politics international. The definitive publisherauthenticated version for Morgan, H.C.M., Randall, J., Lyons, A.J., Oliver, S., Saffer, J., Scott, J.M. \& Nolte, L. (2019) Pebbles in palms: counter-practices against despair, Psychotherapy and politics international, Early view can be found here: https://onlinelibrary.wiley.com/doi/abs/10.1002/ppi.1481

\title{
Pebbles in palms: Counter-practices against despair
}

\section{Author/s}

Hannah C.M. Morgan (corresponding author. Email: h.morgan@herts.ac.uk), James Randall, Amy J. Lyons, Sarah Oliver, Jessica Saffer, Jacqui M. Scott and Lizette Nolte.

All of University of Hertfordshire, Department of Psychology and Sport Sciences, School of Life and Medical Sciences, Health Research Building, College Lane Campus, University of Hertfordshire, Hatfield, AL10 9AB.Tel:01707 286322.Email: DClinPsy@herts.ac.uk

\begin{abstract}
With ongoing news of hardship and suffering in the United Kingdom and throughout the world, in the context of austerity, shrinking public services and increasing social inequalities, it is sometimes difficult not to fall into despair, to feel hopeless and ineffectual. In this paper we consider counter-practices to such despair and hopelessness, which we hope will be helpful to all clinicians.
\end{abstract}

\section{KEYWORDS}

NHS, austerity, public services, hope, clinical psychology, community psychology

\section{1 | Introduction}

We live in challenging times, with widening economic inequalities and growing prejudice (Majumder, 2017; Wilkinson and Pickett, 2010). This has created conditions for large-scale effects on physical and emotional wellbeing, with multiple studies finding that increasing inequalities disproportionately affect the most disadvantaged in society (Bambra \& Garthwaite, 2015; Gelormino, Bambra, Spadea, Bellini \& Costa, 2011; Marmot et al, 2010; Pickett \& Wilkinson, 2017). As clinical psychologists working in the National Health Service (NHS) we bear witness to the individual stories of hardship unfolding within a context of discrimination and injustice. Many work tirelessly and devotedly to find ways to alleviate service users' distress. We sit or stand alongside our clients in their world, using formulation, novel ways of working, and both evidence-based practice and practice-based evidence to think with them about how best to move things forward.

However, the authors often wonder whether this is enough; when our clients are leaving their one-hour weekly appointment only to return to a world where they face endless social, political, economic and familial challenges (Waldegrave, Tamasese, Tuhaka, \& Campbell, 2003). Furthermore, we have persevered through the political imposition of austerity (see Tudor \& von Sommaruga Howard, 2016), necessitating us to work with scarce and diminishing resources (Hillier et al., 2017). We are yet to see whether the rhetoric of "an end to austerity" (BBC News, 2017; Kentish, 2018) will find its way into the lives of our service-users and into the walls of our clinic rooms. Often, we find ourselves faced with the imbalance between what the client or family in front of us require and what resources we can offer; for example, having to provide limited numbers of sessions, having to turn people away who do not fit the 
service criteria, and frantically searching for alternative third-sector services to fill the gap. We find ourselves and our colleagues constantly going above and beyond the call of duty, struggling to respond to ever-increasing numbers of referrals amidst decreasing resources.

As we try to adapt to these difficult environments, we have diminishing time to reflect on our work. Our contexts encourage the tendency to concentrate on the immediate work in front of us, which may lead us to lose sight of the bigger picture. To protect ourselves we are at risk of holding very real issues at arm's length, and not connecting with the lived realities of those who consult with us. Services become more target-driven and business/marketorientated (Diamond, 2008; Smail, 2005). We experience services as becoming increasingly impersonal; we sense a loss of choice and a loss of professional autonomy as interventions become ever more structured and manualised (Binnie, 2015). At times, services have felt like harsh and brutal spaces, for clients as well as for practitioners; we sense reducing morale in our teams, and a loss of job security (e.g. Cotton, 2017; Mulholland, 2017).

From a privileged position, as educated and well-paid professionals, the expectation we place on ourselves is that we should have something helpful to contribute; that we should be able to offer meaningful solutions to the gross injustices we bear witness to. With the skills and training we have been privileged to receive, giving us insights into the many impacts of trauma and inequalities on individuals and communities, comes a responsibility to use it well. Using these knowledges at broader and more meta-levels can at times feel too overwhelming to attempt. (We use the term "knowledges" in the narrative sense, to acknowledge that "alternative knowledges" always exist; see Epston, 1999). Thus, when we consider the complexity of the issues confronting us, it can seem that our contribution, and the contribution of every well-meaning psychologist who came before us, cannot be enough to stem the ongoing crises in our communities and in wider society. At times we can find ourselves trapped, and in a similar predicament to the late David Smail, who ended his last book observing that "the world is in a bloody mess and even though I know, as do many others, what it would look like if we weren't, I have no more viable idea than anyone else how to get there" (Smail, 2005, p. 101).

Within the context of these challenges we find ourselves struggling not to fall into despair, not to lose faith in the NHS, or the ability for our profession to achieve something meaningful in our daily work, and not to be drawn into positions of helplessness. As the NHS reached its $70^{\text {th }}$ anniversary just months ago, in July 2018 , we feel this should have called for celebration, but our feelings have been bitter-sweet. The vision of a health service that is fit to provide health care within a network of support alongside other public services, together representing the shared values of a compassionate and responsible society, is hard to recognise. The NHS is now, it has been argued, a lone institution within "a society where the principles at the NHS's heart have been eroded to scarcity" (Sheers, 2018, para. 7). Alongside so many other caring professions, we feel pressured to do everything, that is, to change the world and fix all of these problems, only to realise how little we can actually do; oscillating then to a position of hopelessness, where we feel we can do nothing. This can result in distancing ourselves from our social responsibilities, justifying our (in)actions, and placing blame elsewhere.

These challenges threaten to take us away from our values, intentions, and the reasons that brought us into the profession of clinical psychology. Values that include: bringing not only our clinical skills to clinical encounters but also our humanity and kindness; a commitment to see people's difficulties within the context of their lives; and finding ways to facilitate change within the wider systems surrounding a person. These values represent an 
underlying ethos of social justice, equality and solidarity in efforts to achieve these. Factors that are considered key attributes of approaches such as community psychology and liberation psychology - developing schools of psychological practice that address adversities beyond the individual, in order to support, facilitate and advocate for oppressed and subjugated groups within and beyond the remit of the "established order" of things. Ultimately, these approaches look to critique psychology and the therapy industry itself (Smail, 2005), address the neoliberal underpinning of the psychology industry (Ferraro, 2016) and training communities (Itten \& Roberts, 2014; Cromby, 2017), and to decolonise (Pillay, 2017) and democratise (Diamond, 2008) psychological and mental health services overall. Holding on to these intentions, practices and their underlying values, can however become very difficult within the current climate of increasing demands and dwindling capacity of austere times - with limits on reflection at the individual and systemic level (Campling, 2006).

\section{2 | THE DROP OF A PEBBLE}

The authors met whilst completing their doctoral training in clinical psychology at the University of Hertfordshire in the UK. We came together as a group and considered what approaches and actions had sustained us in our endeavours over this time. We started to understand the ways in which we had countered despair throughout our work together. We developed the analogy of a pebble dropping into a pond, causing ever-expanding ripples. No matter the size of the pebble, the change it creates can be widespread. It was through this way of understanding our actions that we began to realise we could pursue positive change and achieve something. Our analogy is informed by Bronfenbrenner's (1977) ecological systems model of ways to work beyond just the individual. Indeed, thinking of our actions as pebbles being dropped at particular levels of a wider system appears to restore all sorts of possibilities for our work. We suggest that the impact of such actions is not limited to the systemic level in which one has dropped their pebble; the ripples ensure this impact can be felt, in some shape or form, at many other levels even if we are unaware of this happening. We have conceptualised these potentials and this impact visually in Figure 1.

\section{[FIGURE 1]}

In short, holding these pebbles in our palms and finding ways to drop them at different levels of the model could empower us as clinicians to keep doing what we can not only for the individual, but for the circumstances they find themselves in, and the contexts around us all. This is without necessarily foreseeing what may come thereafter. Indeed, there are many examples in history of actions rippling out from their initial objective and having an impact at a later time (Solnit, 2017). For example, working at a macro-systemic level shifts focus to the overarching cultural context in which an individual resides. At this level, the socio-political contexts influence the narratives that are held by people in society. Research has highlighted the power of political narratives and their impact on the media's portrayal of immigration, highlighting the influence of these narratives in shaping the stories that refugees tell about themselves (Leudar, Hayes, Nekvapil, \& Turner Baker, 2008).

As psychologists, we have developed competencies that enable us to not only provide support at the individual level, but also consider ways in which we can influence the wider system, for example, through use of psychological theory. Together, we have the power to consider, or create, research and use this to help influence the political agenda, both now and 
in the future (e.g. Head, Ellis-Caird, Rhodes, \& Parkinson, 2018; Saffer, Nolte \& Duffy, 2018). However, in order to reach the point of dropping our pebbles, we first need to be able to survive these imperfect systems.

\section{3 | PEBBLES IN PALMS}

To have the freedom to take action [was] to somehow be able to survive the devastation and disappointment that sometimes inevitably occurs in the course of dealing with the tragedies of living. To be able to keep going and not lose hope, [and to be] able to find the humour in the absurdity of seemingly impossible situations. (Cecchin, Lane, \& Ray, 1992, pp. 74-75)

In order to "warm the context" (Burnham, 2005, pp. 4-5) to your own pebble dropping plans, we wish to explore further some of the factors that enabled us to reach such a place. Working through adversity, hopelessness and inaction, we discovered practices that could sustain us and counter that despair. To drop a pebble was, for us, a discovery of the freedom to take action - do something that could help. We hope that what follows will allow you to surpass that absurdity of imperfect and restricting systems and discourses, in order to move towards a context in which we and others can survive and thrive. In short, to find the "difference that makes the difference" (Bateson, 1979, p. 99).

Throughout clinical training and practice, individuals are faced with a constant process of identifying and addressing a range of challenges when faced with unique and complex situations. Within our training, we were grouped together on the one hand, within the context of a Problem-Based Learning (PBL) group, but also on the other hand, through our shared sense of values which we came to realise over time. Recognising this, we planned intermittent meetings to consider what factors had allowed us to progress through training in a way that allowed us to overcome ruptures in our relationships and maintain a sense of group cohesion and/or solidarity through our differences. We were curious to explore how we had developed such innovative and creative ideas, and worked productively and effectively together, with minimal disruption or conflict. During one of our later meetings, we reviewed our experiences together, looked back over reflective diaries, and considered the work we had achieved collectively over the three years of training. Through this process, we began to draw out common themes from our discussions, wrote these down and revisited them - checking-in with one another to explore individual and group experiences around these. We had begun with sharing an individual exercise taken from the Narrative Therapyinformed Tree of Life approach (Ncube, 2006), that enabled each of us to bring awareness to influences, difficulties and inspirations that had brought us into this work and into this particular training. From the sharing of these emerged a "forest of life" (Denborough, 2008, p.81) in which, through the value of collaboration we recognised that together we have more reach, resources and strength than as individuals. Our forest contains connections to those who gave us ideas so generously; not least our course programme, providing the opportunity to consider a critical psychology stance, and those we met along the way introducing us to concepts of imperfection, hope and rewilding. Ultimately, we identified a range of factors that we feel enabled us to survive the devastations and disappointments we faced during these last few years. These include reasonable hope; small acts of resistance; being stronger together; and sustaining ourselves over time. We will explore each factor in more depth below. 
Beyond the scope of this paper, but of which seemed pivotal to our group identity, were other themes around the use of humour through the absurd and at times of feeling distraught; a shared vulnerability not only in relation to the broader context of societal changes that seemed to disempower, but also in our shared state of being trainees - with a collective history of turbulent struggles to secure a place on training, having had to experience and live within competitive contexts and thrive as individuals - often characterised by "perfectionist" drives. It was also evident from our discussions, that there was a sense of containment held by our kind and supportive facilitator throughout, who became our friend and colleague over time - and ultimately, a collaborator and co-author on this paper.

\section{1 | Reasonable hope}

Despair might at times be a reasonable response to our experiences. There is an argument that those in power may even wish for us to remain hopeless, without power or reason to act. However, to remain within a position of despair and hopelessness is not fruitful. Hope can sustain us when circumstances impose despair upon us, but it does not necessarily mean wishing for or wanting something to change. Rather, hope can be the energy that connects us to our situation and drives us to act in response to it. Therefore, we extend to ourselves "a permanent invitation to think about hope" (Edey \& Jevne, 2003, p.47). We particularly value Weingarten's idea of "reasonable hope" (2010, p. 5), with a focus on translating this principle into praxis; namely, conceptualising hope as a verb, rather than a noun. "Reasonable hope" refers to actions not, as hope does, to a feeling that may or may not be accessible. Hope is often considered the attribute of an individual; in contrast "reasonable hope" can be the actions of one or many people. In this light, we are not static in positions of reasonable hope, but are in a constant and dynamic process of practising reasonable hope. As such, reasonable hope becomes something we can do together (Weingarten, 2005):

When we work ... within a framework of reasonable hope, we are not casting about for the perfect solution but are considering what may be good enough. From this perspective, we realize that small actions need not be trivial. They may also have ripple effects. (Weingarten, 2010, p. 19)

In line with this idea of reasonable hope we were also inspired by the essays of Rebecca Solnit (2016) who is quick to point out what hope is not, namely "the belief that everything was, is, or will be fine" (p. xi). She too advocates a type of hope that demands action. This is similar to Smail's position that hopes, wishes and vision, without action, are equivalent to a "magical voluntarism" (Smail, 2005, p.28) - an effective route to stagnation, rather than progress. Thus, within our imperfect systems we have been able to move from positions of overwhelming paralysis to positions of hope; that is, from doing nothing to doing something.

\section{2 | Small acts of resistance}

We started to discuss the times when we noticed ourselves or our colleagues acting in line with our shared values and against the dominant narratives of despair or apathy. To notice the "tiny and temporary victories" (Solnit, 2016, p. xxii) and potential for other partial "victories" within the confounds of the systems in which we act. Examples included stepping outside of a "model"; offering more than the "allowed" number of appointments, advocating 
for alternative models of treatment when indicated (Nel, 2012); going beyond the manual; "bending the frame" (Eversole, 1997, p.23) and engaging in political and policy debates as a profession (e.g. Psychologists for Social Change, see www.psychchange.org). We noticed that together we could uncover, for ourselves and our clients, the "small acts of living" (Wade, 1997, p. 32) that led to "everyday resistance" (Wade, 1997, p. 37). These small acts or steps, if acknowledged and celebrated, help to build an alternative story (White \& Epston, 1990). A story in which we, as clinicians, are working and practicing ethically, in line with our values, and at the same time resisting the despair narratives that we found so dominant. At the same time, these small acts of resistance are said to promote broader and more substantial acts towards change in the longer term (Wade, 1997); to act in whatever small way now, means that we are more likely to act in such a way in the future, and perhaps to a more significant extent. An example of this is the small ways in which practitioners question and challenge what they deem to be unhelpful and/or unethical diagnostic practices leading to more sustained and collective action more likely over time - such as a shift from a focus on language usage within reports, to wider-scale activism and protest (Randall-James \& Coles, 2018). As in our model above (Figure 1) these small acts, or "pebbles" as we came to refer to them, also had the potential to ripple out and have an impact on a much grander scale.

History tells us, however, that sometimes resistance needs a friend.

\section{3 | Stronger together}

These acts of resistance can feel risky and can require courage through relational risk-taking to build a trust between people (Mason, 2005). We are therefore inspired by Reynolds' concept of "imperfect ally positions" (2010, p. 13), in which standing alongside means taking collective ownership of issues that should not be made to reside within individuals. Solidarity, community and collective action can contribute to a shared social identity (Tajfel \& Turner, 1979). Within a collective, the values we hold as individuals are recognised and validated, making us more likely to act in line with these values and feel a shared humanity with wider groups of people.

We have experienced this ourselves in our training when we came together for the Problem-Based Learning group task which inspired this paper (see Nel et al., 2008). As individuals, the tasks put before us often led to feelings of hopelessness, however we found that we were more likely to feel that change was possible when working together, and that this led to both individual and group action towards meaningful change. Through this social categorising of selves we could also pursue political change and become activists by directing "collective action" through (re)defining self-categories (Reicher \& Hopkins, 1996, p.300).

In the wider context, this is what clinical psychology could potentially be doing; re-defining its social identity in order to instigate political change. As small but not insignificant exemplary pebbles, this could involve blurring lines between clinical practice and community psychology by expanding our thinking beyond the clinic, or contributing to critiques of the therapy industry. Some clinical psychologists, and many who may define themselves otherwise, including community workers, community psychologists and youth workers, stress the importance of developing preventative rather than reactive interventions (e.g. Harper, 2016), as individual therapy will never be available to all who could benefit from it, and nor should we expect individual interventions to be the most effective solution to collectively-held social issues. Rather than isolate ourselves as a profession, we can be involved in community work, share these ideas and learn from those with lived or other experiences to our own. 


\section{4 | Sustaining ourselves}

We noticed the additional and ongoing enthusiasm it takes to maintain these practices, and the need for ways to look after ourselves to sustain these causes. Failure to do so can lead us to lose faith and energy to do our work, to remain passionate and available to our clients, and practice in line with the beliefs and values that initially brought us to the work we do (Reynolds, 2011). As Figley (2002) identified, the importance of self-care and considering our own wellbeing in this endeavour cannot be underestimated. Here, we again borrow the words of Vikki Reynolds, who defined sustainability as:

an aliveness, a spirited presence, and a genuine connectedness with others. It requires more than keeping-on, more than resisting burnout, more than keeping a desperate hold onto hope; and yet it encompasses all of these capacities. We are sustained in the work when we are able to be fully and relationally engaged, stay connected with hope, and be of use to clients across time. $(2011$, p. 32)

During our exploration of these ideas together we noticed that each of us had very different but no less important ways of looking after ourselves and protecting ourselves to some extent against despair. For some this involved personal therapy, for others it was getting closer to nature and the outdoors, and some of us turned to the arts (music, dance, theatre) or physical activity. For all, the support we experienced in our relationships with each other and with our allies in our wider contexts were invaluable.

In our experience, it is easier to stay connected to hope when we stay connected to each other and to the meaning of what we do. As we each progress forward in our careers we find hope and continued sustenance in our practices of resistance against social injustices, through the connections we hold to each other in our expanding forest of life. Reconnecting from time to time, sharing small successes, supporting each other through troubling times, and the awareness that we are not alone in these endeavours can renew our energy in these challenging times.

\section{4 | CONCLUSION}

Even in the most critical and damning of contexts, even in "this bloody mess" (Smail, 2005, p. 101), the question can be asked "What then must we do?" (This is the question posed by the title of David Smail's poignant concluding chapter in the final publication before his death). Instead of being overcome by despair and feeling powerless we have a vision of reviving our work (and learning) environments; believing that when acting in line with our values and ethics, each act makes a difference and contributes to a collective change. As we reflected on our preferred actions and their potential to counter despair, once again we imagined the ripples from our pebbles broadening their spread. We all have the power to throw pebbles out into the world. We hold onto the hope that our pebbles will be enough, enough to make even the smallest of changes. We hold onto this hope both as clinical psychologists, and also as persons of the world. Thus, we have moved from a position of feeling paralysed; doing nothing, through a position of desperation and desire to do everything; to a position of hope that we can do something. To our clients, we owe that much. 


\section{References}

Bateson, G. (1979). Mind and nature: A necessary unity. New York, NY: Dutton.

Bambra, C., \& Garthwaite, K. (2015). Austerity, welfare reform and the English health divide. Area, 47, 341-343. https://doi.org/10.1111/area.12191

BBC News. (2017, June 13). Newspaper headlines: May's mea culpa and the end of austerity. $B B C$ News. Retrieved June 21, 2017 from http://www.bbc.co.uk/news/blogs-the-papers40255847

Binnie, J. (2015). Do you want therapy with that? A critical account of working within IAPT. Mental Health Review Journal, 20(2), 79-83. https://doi.org/10.1108/MHRJ-11-2014-0044

Bronfenbrenner, U. (1977). Toward an experimental ecology of human development. American Psychologist, 32(7), 513-531. http://dx.doi.org/10.1037/0003-066X.32.7.513

Burnham, J. (2005). Relational reflexivity: A tool for socially constructing therapeutic relationships. In Flaskas, Mason \& Perlesz (eds.) The space between: Experience, context and process in the therapeutic relationship (pp. 1-17). London, UK: Karnac Books.

Campling, P. (2016). The opportunities and pitfalls of reflective practice in an age of austerity. Psychotherapy and Politics International, 14(1), 48-60. https://doi.org/10.1002/ppi.1372

Cecchin, G., Lane, G., \& Ray, W. A. (1992). Irreverence: A strategy for therapists' survival. London, UK: Karnac Books.

Cotton, E. (2017). Surviving work in healthcare: Helpful stuff for people on the frontline. Abingdon, UK: Routledge.

Cromby, J. (2017). Ten suggestions for critical teaching in psychology. In Newnes and Golding (Eds.) Teaching critical psychology (pp. 41-58). London, UK: Routledge.

Denborough, D. (2008). Collective narrative practice: Responding to individuals, groups, and communities who have experienced trauma. Dulwich Centre Publications.

Diamond, B. (2008). Opening up space for dissension: A questioning psychology. In A. Morgan (Ed.), Being human: Reflections on mental distress in society (pp. 174-189). Monmouth, UK: PCCS Books.

Edey, W., \& Jevne, R. F. (2003). Hope, illness, and counselling practice: Making hope visible. Canadian Journal of Counselling, 37(1), 44-51.

Epston, D. (1999). Co-research: The making of an alternative knowledge. In Narrative therapy and community work: A conference collection (Vol. 1, pp. 137-156). Adelaide, Australia: Dulwich Centre Publications.

Eversole, T. (1997). HIV mental health for the 21st century. In M. Winiarski (Ed.), Psychotherapy and counseling: Bending the frame (pp. 23-38). New York, NY: NYU Press.

Figley, C. R. (2002). Compassion fatigue: Psychotherapists' chronic lack of self care. Journal of Clinical Psychology, 58(11), 1433-1441. https://doi.org/10.1002/jclp.10090

Ferraro, D. (2016). Psychology in the age of austerity. Psychotherapy and Politics International, 14(1), 17-24. https://doi.org/10.1002/ppi.1369 
Gelormino, E., Bambra, C., Spadea, T., Bellini, S., \& Costa, G. (2011). The effects of health care reforms on health inequalities: A review and analysis of the European evidence base. International Journal of Health Services, 41(2), 209-230. https://doi.org/10.2190/HS.41.2.b

Harper, D. (2016). Beyond individual therapy. The Psychologist, 29(6), 440-444.

Head, A., Ellis-Caird, H., Rhodes, L., \& Parkinson, K. (2018). Transforming identities through Transforming Care: How people with learning disabilities experience moving out of hospital. British Journal of Learning Disabilities, 46(1), 64-70. https://doi.org/10.1111/bld.12213

Hillier, M., Bacon, R., Boswell, P., Elphicke, C., Evans, C., Flint, C., . . \& Trevelyan, A.-M. (2017). Financial sustainability of the NHS: 43rd report of the Committee of Public Accounts. Retrieved November 9, 9, 2018 from http://www.publications.parliament.uk/pa/cm201617/cmselect/cmpubacc/887/88702.h $\mathrm{tm}$

Itten, T., \& Roberts, R. (2014). The new politics of experience and the bitter herbs. Monmouth, UK: PCCS Books.

Kentish, B. (2018, October 3). Theresa May declares 'austerity is over' after eight years of cuts and tax increases. The Independent. Retrieved from https://www.independent.co.uk/news/uk/politics/theresa-may-austerity-end-overspeech-conservative-conference-tory-labour-a8566526.html

Leudar, I., Hayes, J., Nekvapil, J., \& Turner Baker, J. (2008). Hostility themes in media, community and refugee narratives. Discourse \& Society, 19(2), 187-221. https://doi.org/10.1177/0957926507085952

Majumder, M. (2017, January 23). Higher rates of hate crimes are tied to income inequality. $\begin{array}{lllll}\text { FiveThirtyEight. } & \text { Retrieved } & \text { November } & 9 & 2018 \text { from }\end{array}$ https://fivethirtyeight.com/features/higher-rates-of-hate-crimes-are-tied-to-incomeinequality/

Marmot, M., Allen, J., Goldblatt, P., Boyce, T., McNeish, D., \& Grady, M. (2010). Fair society, healthy lives. The Marmot Review, 14. Strategic Review of Health Inequalities in England post-2010, Institute of Health Equity. Retrieved from http://www.instituteofhealthequity.org/resources-reports/fair-society-healthy-lives-themarmot-review/fair-society-healthy-lives-full-report-pdf.pdf

Mason, B. (2005). Relational risk-taking and the therapeutic relationship. In C. Flaskas, B. Mason, \& A. Perlesz (Eds.), The space between: Experience, context and process in the therapeutic relationship (pp. 157-170). London, UK: Karnac Books.

Mulholland, H. (2017, June 20). Eleanor Smith MP: 'NHS staff are undervalued - and demoralised'. The Guardian Newspaper. Retrieved from https://www.theguardian.com/society/2017/jun/20/eleanor-smith-first-black-mpmidlands-nursing-nhs

Ncube, N. (2006). The tree of life project: Using narrative ideas in work with vulnerable children in Southern Africa. International Journal of Narrative Therapy and Community Work, (1), 3-16.

Nel, P. (2012). The trouble with clinical psychology. Clinical Psychology Forum, 235(7), 18-22. 
Nel, P. W., Keville, S., Ford, D., McCarney, R., Jeffrey, S., Adams, S., \& Uprichard, S. (2008). Close encounters of the uncertain kind: Reflections on doing problem-based learning (PBL) for the first time. Reflective Practice, 9(2), 197-206. https://doi.org/10.1080/14623940802005582

Pickett, K. E., \& Wilkinson, R. G. (2017, February 8). Immorality of inaction on inequality. British Medical Journal, 356. https://doi.org/10.1136/bmj.j556

Pillay, S. R. (2017). Cracking the fortress: Can we really decolonize psychology? South African Journal of Psychology, 47,135-140. https://doi.org/10.1177/0081246317698059

Randall-James, J. \& Coles, S. (2018). Questioning diagnoses in clinical practice: A thematic analysis of clinical psychologists' accounts of working beyond diagnosis in the United Kingdom. Journal of Mental Health, 27 (5) 450-456. https://doi.org/10.1080/09638237.2018.1437599

Reicher, S., \& Hopkins, N. (1996). Seeking influence through characterizing self-categories: An analysis of anti-abortionist rhetoric. British Journal of Social Psychology, 35(2), 297-311.

Reynolds, V. (2010). Fluid and imperfect ally positioning: Some gifts of queer theory. Context, $111,13-17$.

Reynolds, V. (2011). Resisting burnout with justice-doing. International Journal of Narrative Therapy and Community Work, 4, 27-45.

Saffer, J., Nolte, L., \& Duffy, S. (2018). Living on a knife edge: The responses of people with physical health conditions to changes in disability benefits. Disability \& Society. https://doi.org/10.1080/09687599.2018.1514292

Sheers, O. (2018). 70 years of the NHS: A revolution that is reborn every day. The Guardian. https://www.theguardian.com/society/2018/jun/24/nhs-cultural-revolution-healthservice-staff-patients

Smail, D. J. (2005). Power, interest and psychology: Elements of a social materialist understanding of distress. London, UK: PCCS Books.

Solnit, R. (2016). Hope in the dark: Untold histories, wild possibilities. Edinburgh, UK: Canongate Books.

Solnit, R. (2017, March 13). Protest and persist: Why giving up hope is not an option. The Guardian. $\quad$ Retrieved November 2018 9, from https://www.theguardian.com/world/2017/mar/13/protest-persist-hope-trumpactivism-anti-nuclear-movement

Tajfel, H., \& Turner, J. C. (1979). An integrative theory of intergroup conflict. In W. G. Austin, \& S. Worchel (Eds.), The social psychology of intergroup relations (pp. 33-37). Monterey, CA: Brooks/Cole.

Tudor, K., \& von Sommaruga Howard, T. (2016) Editorial: Special Issue: Neoliberalism and Austerity. Psychotherapy and Politics International, 4(1), 3-4. https://doi.org/10.1002/ppi.1367

Wade, A. (1997). Small acts of living: Everyday resistance to violence and other forms of oppression. Contemporary Family Therapy, 19(1), 23-39. 
Waldegrave, C., Tamasese, K., Tuhaka, F., \& Campbell, W. (2003). Just therapy: A journey. Adelaide, Australia: Dulwich Centre Publications.

Weingarten, K. (2005). Cancer, meaning making, and hope: The Treatment Dedication Project: Comment. Families, Systems \& Health, 23(2), 155-160. DOI: 10.1037/10917527.23.2.155

Weingarten, K. (2010). Reasonable hope: Construct, clinical applications, and supports. Family Process, 49(1), 5-25. https://doi.org/10.1111/j.1545-5300.2010.01305.x

Wilkinson, R., \& Pickett, K. (2010). The spirit level: Why equality is better for everyone. Penguin Books.

White, M., \& Epston, D. (1990). Narrative means to therapeutic ends. New York, NY: WW Norton.

\section{AUTHOR BIOGRAPHIES}

Hannah C. M. Morgan, James Randall, Amy J. Lyons, Sarah Oliver, Jessica Saffer, and Jacqui M. Scott are all Clinical Psychologists who completed the Doctorate in Clinical Psychology Programme at the University of Hertfordshire. Lizette Nolte is a Clinical Lecturer on the Doctorate in Clinical Psychology Programme at the University of Hertfordshire. 